4. Auf gerichtliche Chemie bezügliche Methoden. von

\title{
H. Bayerlein.
}

Zum Nachweis von Aloë bei gerichtlich-chemischen Untersuchungen schlägt Pierre Apéry ${ }^{1}$ ) die Einwirkung von Eisenchlorid auf das Gummiharz als Erkennungs-Reaction vor.

Das zu untersuchende Material wird mit Alkohol extrahirt, der filtrirte alkoholische Auszug wird zur Trockne verdampft, der Rückstand mit warmem Wasser aufgenommen, filtrirt und das Filtrat mit Bleiacetat gefällt. Aus dem Filtrat des Bleiniederschlages wird nach dem Concentriren auf dem Wasserbade der Bleiüberschuss durch Kochen mit kohlensaurem Natron entfernt und das Filtrat mit Essigsäure oder Salpetersäure neutralisirt. Bei Gegenwart von Aloë gibt diese Flüssigkeit auf Zusatz einiger Tropfen einer verdünnten Eisenchloridlösung eine deutlich rothbraune Färbung, welche noch in einer Verdünnung von 1 Theil Aloë auf 2000-3000 Theile Wasser auftritt.

Nach Brouardel geben tannin- und phenolhaltige Substanzen, wie Kolanüsse, Arecanüsse etc. mit Eisenchlorid ebenfalls eine bratunröthliche Färbung, da aber diese tonischen Mittel bei verbrecherischer Anwendung der Aloë zur Herbeiführung von Abortus gewöhnlich nicht zugleich Verwendung finden und andere Drastica, wie Sabina, Absynthium, abführende Gummiharze etc. die beschriebene Reaction nicht liefern, so erscheint die Methode als brauchbar zum gerichtlich-chemischen Nachweis von Aloë.

Den Nachweis von Blut mit Hülfe der Photographie bespricht Jeserich ${ }^{2}$ ) in einer Abhandlung über die Photographie im Dienste der Criminaljustiz, auf die im Uebrigen nur verwiesen werden kann. Sosoll sich abgewischtes Blut an Messern, Beilen etc. auf dem Photogramm erkennen lassen, indem in Folge der intensiven Beleuchtung die Wischstreifen deutlich zum Vorschein kommen.

Dass man Menschenblut von Thierblut an der Grössenverschieden. heit der Blutkörperchen unterscheiden könne, ist mehrfach behauptet und eben so oft bestritten worden. Nach Jeserich ist der Nachweis, dass Menschenblat vorliegt mit Sicherheit zu führen. Von Sängethieren haben nur das Kameel und der Elephant grössere Blutkörperchen als der Mensch; wo der ersten beiden Blut ausgeschlossen ist, wie für gewöhnlich bei uns, ist mit Sicherheit zu sagen, es liegt Menschenblut vor, sobald die Blutkörperchen $78 / 10000 \mathrm{~mm}$ gross sind.

1) Mitth. d. Soc. Imp. de Med. in Constantinopel; durch Zeitschrift des. allgem. österr. Apotheker-Vereins 50, 766.

2) Pharm. Centralhalle 32, 708. 